\title{
Effects of Wastewater Treatment Plant Effluent on Survival, Growth, and Vitellogenin Concentrations of Fathead Minnows (Pimephales promelas)
}

\author{
Lisa A. Griffin ${ }^{\mathrm{a}}$ and Dr. Elisabeth A. Harrahy ${ }^{\mathrm{a}}$
}

\begin{abstract}
Concern over pharmaceuticals and personal care products (PPCPs) in surface waters has increased as scientists have detected these contaminants in streams and rivers nationwide. One source of PPCPs is wastewater treatment plants (WWTPs), where some PPCPs are being delivered and then discharged to receiving waters in effluent. Estrogens, the primary female sex hormones, have been found in natural and synthetic forms in effluent and in receiving waters. Field and laboratory studies were carried out to determine if a local WWTP's effluent affects survival, egg production, and vitellogenin (an egg precursor protein) concentrations in fathead minnows. Results from a 24-day field study showed no significant difference in survival or egg production between fish caged at sites located upstream and downstream of the WWTP effluent pipe. Vitellogenin was detected in some male fish at both sites. A comparison of male fish that produced vitellogenin showed higher concentrations in those located downstream. Because there may be other sources of estrogens or estrogen mimics to the stream, acute and chronic whole effluent toxicity (WET) tests were conducted with larval fathead minnows, and a reproduction assay was conducted with adult fathead minnows in the laboratory. Results of the WET tests showed no significant difference in survival among fish exposed to different dilutions of whole effluent. The laboratory reproduction assay showed no significant differences in survival or egg production between fish in $100 \%$ effluent and control treatments. Vitellogenin was detected in all male fish analyzed, including controls. This indicates there may be other sources of estrogenic compounds in the laboratory as well. While biomarkers such as vitellogenin may be more sensitive than other endpoints such as growth or reproduction, it is important to have a good understanding of their specificity. Given the large number of compounds that may act as estrogen mimics, the specificity of vitellogenin is low compared to some other biomarkers, and it may be better utilized in combination with other biomarkers and other forms of evidence of endocrine disruption in both the field and laboratory. Combining field and laboratory studies can provide a better understanding of the potential effects of WWTP effluent on aquatic organisms.
\end{abstract}

Keywords: Pharmaceuticals; Fathead Minnows; Wastewater Treatment Plants; Vitellogenin

\section{Introduction}

Use of pharmaceuticals and personal care products (PPCPs) has increased in recent decades. Pharmaceuticals may be excreted unchanged or as metabolites (Loffler, Rambke, Meller \& Ternes, 2005) and also poured or flushed down the drain. Personal care products are often washed down the drain. However, the WWTPs that receive these compounds are not designed to treat them, and can act as a point source for contamination (Zorita, Martinsson \& Mathiasson, 2009). Concern over PPCPs in surface waters has grown since Kolpin et al. (2002) published the results of a nationwide reconnaissance study in which 82 of 95 PPCPs analyzed were detected in streams. PPCPs detected included members of 15 classes of pharmaceuticals, including antidepressants, antibiotics, non-prescription drugs, and hormones.

Estrogens (female sex hormones) such as estrone and 17 $\beta$-estradiol have been detected in WWTP effluents (Servos et al., 2005) and in receiving waters (Kolpin et al., 2002). While Korner et al. (2000) showed that estrogenic activity can be reduced by $90 \%$ during the WWTP process, the estrogens that make it through the plant are considered pseudopersistent in receiving waters due to constant input. Because estrogens and other PPCPs are typically delivered to the environment as a dynamic (ever-changing) mixture, it can be difficult to determine the risk they pose to aquatic organisms.
By assessing numerous endpoints, researchers can obtain a better understanding of the impacts of effluents on aquatic organisms. For example, Liney et al. (2006) studied the effects of WWTP effluent on early life stage roach (Rutilus rutilus) and measured survival, alteration of gonads, kidney development, genotoxic damage, immune function, and vitellogenin concentration. Vitellogenin is an egg-yolk precursor protein that is normally found only in female fish, but its production can be activated in males through introduction of estrogens or estrogen-mimicking compounds (Ishibashi et al., 2001). Vitellogenin has become a commonly used biomarker of endocrine disruption, and enzyme-linked immunosorbent assay (ELISA) kits that allow measurement of vitellogenin in various species, including fathead minnows, are available.

The WWTP in Whitewater, WI discharges approximately 1.9 million gallons per day (MGD) of treated wastewater to Whitewater Creek. It is the only WWTP that discharges to Whitewater Creek. After an initial screening to collect large debris, the influent is collected in primary clarifiers where solids settle to the bottom for later removal, and fat and grease float to the top where they can be skimmed from the surface. After this primary treatment phase, the wastewater flows into buildings that house rotating biological contactors (RBCs) for the secondary (biological) treatment phase. Each RBC is made up of hundreds of thin polyvinyl chloride (PVC) plates that offer a large amount of surface area 
for aerobic microbes that consume the organic wastes. PostRBC treatment includes additional solid waste removal by secondary clarifiers, and finer particulate removal by anthracite media filters. Alum is added to remove phosphorus. Disinfection is accomplished using ultraviolet (UV) light from May through September, and the final effluent is aerated just prior to discharge to Whitewater Creek (Munderlin, 2013). Whitewater Creek, located in the Lower Rock River watershed, is a fourth order stream in the reach where our study sites were located. Surrounding land use in the area of our study is a mix of residential and urban.

Fathead minnows (Pimephales promelas) are widely distributed in North America. They are an important prey fish for larger fish and birds, and are widely used as bait by anglers. With an average length of $50 \mathrm{~mm}$, this omnivorous fish feeds on algae and macroinvertebrates. Males show several secondary sexual characteristics upon sexual maturation which include a fat pad on their backs, and dorsal banding and nuptial tubercles on their snouts (USEPA, 2002a). Females lay between 100-150 eggs per clutch and males then guard their nests, keeping the eggs oxygenated and free of debris and fungus. Optimum egg production occurs at a water temperature of $19^{\circ}-25^{\circ} \mathrm{C}$ (Corsi, Klaper, Weber, \& Bannerman, 2011). Their lifespan is generally less than three years. Fathead minnows are fairly easy to culture and are a model test organism for whole effluent toxicity (WET) testing.

WET tests are often required as part of discharge permits granted to facilities that discharge effluent to surface waters, and are designed to assess potential toxicity of whole effluent on aquatic organisms. Since effluents are a mixture of treated wastewater and various chemicals, both inorganic and organic, WET tests allow more rapid testing of toxicity than would be possible by conducting a series of single chemical tests, although it can be difficult to determine what component of the effluent is responsible for any toxicity that is observed. There are two types of WET tests: acute and chronic. Acute tests are shorter in duration and focus on survival as an endpoint, while chronic tests are longer in duration and focus on sublethal endpoints (USEPA, 2002a \& 2002b).

The purpose of this study was to determine if effluent discharged by a local WWTP affects survival, egg production, and/or vitellogenin concentrations in fathead minnows. Specific objectives were to 1) conduct a field reproduction assay with caged, adult fathead minnows, 2) conduct laboratory acute and chronic WET tests with larval fathead minnows, and 3 ) conduct a laboratory reproduction assay with adult fathead minnows.

\section{Experimental Procedures}

University of Wisconsin- Whitewater Institutional Animal Use and Care Committee (IACUC) approval was obtained (case number H12307002Q) prior to all work conducted with fathead minnows.

\section{Field Reproduction Assay}

We conducted a 24-day field study using adult fathead minnows housed in flow-through fish cages borrowed from the United States Geological Survey (Madison, Wisconsin).
Each fish cage contained six in-situ breeding chambers. One male and two female fish were placed in each in-situ breeding chamber. Also placed in each in-situ breeding chamber was a removable PVC substrate on which females could lay eggs. Three cages (for a total of 18 in-situ breeding chambers) were placed at each of two sites on Whitewater Creek. Our upstream site was located approximately $400 \mathrm{~m}$ upstream of the WWTP discharge pipe, and our downstream site was located approximately $420 \mathrm{~m}$ downstream of the WWTP discharge pipe. Each in-situ breeding chamber was checked daily to determine survival of adult fish, to look for eggs, takes notes on secondary sexual characteristics, and feed the fish. Any eggs present were counted, removed from the substrate, and placed in a container containing $95 \%$ ethanol. Fish were fed a pinch of pelleted \#2 trout chow (Aquatic BioSystems, Inc., Fort Collins, CO) and a cube of freezedried tubifex worms (AquaSelect, Commack, NY). Dissolved oxygen (DO), $\mathrm{pH}$, and conductivity were measured with a Quanta meter (Hach Co., Loveland, CO). Wind speed and air temperature were measured using a Kestrel meter. Stream current velocity was measured using a Swoffer flow meter (Wildlife Supply Co, Yulee, FL). Temperature was recorded every 15 minutes via HOBO data loggers (Onset Computers, Bourne, MA) attached to one cage at each site and these data were downloaded at the end of the test period.

At the end of the experiment, each male fish was euthanized using tricane methanesulfoate (MS-222; $1 \mathrm{~g} / \mathrm{L}$ ) (Western Chemical, Ferndale, WA). The caudal vein was severed and blood drawn into a micro-hemocrit capillary tube. The sample was plugged at one end with hemato-seal capillary tube sealant and centrifuged for three minutes at $15,000 \mathrm{~g}$ to separate the plasma from other blood components. Plasma was removed from the capillary tube via 1cc plastic syringe and a sterile $27 \mathrm{G}$ needle (Becton Dickinson, Fisher Scientific, Pittsburgh, PA). Plasma was stored in a $1.5 \mathrm{~mL}$ capped plastic microcentrifuge tube at $-20^{\circ} \mathrm{C}$ prior to vitellogenin analysis.

Concentration of vitellogenin was determined for each male fish using an enzyme-linked immunosorbent assay (ELISA) kit for fathead minnows (Cayman Chemical, Ann Arbor, MI). Samples were analyzed according to directions included in the kit. Blood plasma was diluted 1:50. The plate was read at an absorbance of $450 \mathrm{~nm}$ on a Spectra Max plate reader (Molecular Devices, Sunnyvale, CA), and concentrations determined using Sortmax Pro software. The lowest standard included in the kit (limit of detection) was $0.05 \mathrm{ng} \mathrm{Vtg} / \mathrm{mL}$, and the highest was $50 \mathrm{ng} \mathrm{Vtg} / \mathrm{mL}$. QA/QC procedures included running blanks, standards and samples in duplicate wells.

\section{Acute and Chronic WET Tests}

Fathead minnow larvae used in the WET tests were cultured in an environmental chamber, set at $25^{\circ} \mathrm{C}$. Eight five-gallon aquaria were used as breeding tanks. Each breeding tank housed two breeding units separated by a plastic tank divider. Each breeding unit consisted of one male and two female adult fathead minnows. Tanks were aerated and filtered. A four-inch section of three-inch PVC pipe (cut in half) was added to each side of the tank as a substrate for eggs. Tanks were renewed with dechlorinated tap water daily, and fish were fed frozen brine shrimp (Naja Aquarium 
and Pet Supply, Milwaukee WI) and salmon starter (Aquatic Biosystems Inc., Fort Collins, CO) twice daily. If eggs were produced, they were counted on the substrate and the substrate was returned to the aquarium so the male could keep them free of fungus and well-oxygenated. When eggs reached the "eyed" stage, they were removed from the breeding tanks and placed into a hatching tank containing four inches of dechlorinated tap water. We followed USEPA (2002b) protocol for rearing larvae. Larvae were fed newly hatched Artemia nauplii (Argentemia Gold brine shrimp cysts, Argent Chemical Labs, Redmond, WA) twice daily. Water quality parameters (DO, conductivity, $\mathrm{pH}$, temperature, and ammonia) were monitored daily in breeding and hatching/larval tanks. Ammonia concentrations were monitored using $\mathrm{HACH}$ test strips (HACH Co., Loveland, $\mathrm{CO})$.

In both the acute and chronic WET tests, 10 larval fathead minnows (six days old in the acute, $<24$ hours old in the chronic test) were placed in each of four replicate borosilicate glass $(600 \mathrm{~mL})$ beakers per treatment, each containing $200 \mathrm{~mL}$ solution. Treatments consisted of $0,6.25$, $12.5,25,50$ and $100 \%$ effluent. Beakers were held at $25^{\circ} \mathrm{C}$ with a photoperiod of 16 hours light, 8 hours dark. Dilutions were made using dechlorinated tap water, which also served as our control water. Composite samples of effluent were collected from the WWTP mid-morning on day zero (both tests) and every three days thereafter (chronic test) in plastic cubitainers. Unused effluent was stored in the cubitainers at $4^{\circ} \mathrm{C}$ and allowed to acclimate to room temperature prior to renewal. Solutions were replaced daily, and the test was run for 96 hours (acute) or seven days (chronic). Fish were not fed during the acute WET test. Fish were fed two pipet drops of resuspended brine shrimp nauplii daily in the chronic WET test. Water quality parameters (DO, conductivity, $\mathrm{pH}$, temperature, and ammonia) were monitored daily. Survival was recorded daily in both tests. Growth was measured as dry weight at the end of the chronic WET test. Fish were consolidated across replicates for each treatment, placed in pre-weighed aluminum pans, and dried in an oven at $60^{\circ} \mathrm{F}$ until they reached a constant weight. Dry weight was measured to the nearest mg using a Mettler balance.

\section{Laboratory Reproduction Assay}

Because there may be other sources of estrogens and estrogen-mimics in the field, we conducted a reproduction assay in the laboratory in which fish were exposed directly to whole effluent. We followed the U.S. EPA's short-term reproduction assay method, originally published by Ankley, Jensen, Kahl, Korte, \& Makynen (2001). Two male and four female adult fathead minnows were housed in each of four replicate glass aquaria (20L) containing $10 \mathrm{~L}$ of $100 \%$ effluent or control water (dechlorinated tap water). Aquaria were aerated and kept in an environmental chamber set at $25^{\circ} \mathrm{C}$ with a photoperiod of 16 hours light, 8 hours dark. Effluent was collected from the Whitewater WWTP every two days, between 7:00 and 8:30 AM. Forty liters of effluent were hauled up with a rope and bucket and placed in a $20-\mathrm{L}$ carboy or 2 10-L cubitainers. Effluent was stored in the environmental chamber until solutions were changed out. Water and effluent were changed every two days. Survival, egg production, and secondary sexual characteristics were monitored daily. Eggs were counted, removed from the substrate and placed in a solution of $95 \%$ ethanol. Fish were fed frozen brine shrimp and trout chow twice daily. Water quality parameters (DO, conductivity, $\mathrm{pH}$, temperature, and ammonia) were monitored daily. Chlorine was measured in both the effluent and dechlorinated tap water during change outs using $\mathrm{HACH}$ test strips. At the end of the test all fish were euthanized in MS-222 (1 g/L). Male fish were measured (length) and weighed. Blood plasma was collected and concentration of vitellogenin was measured as described for the field reproduction assay.

\section{Data Analysis}

Field reproduction assay survival data were compared using contingency table analysis to determine if placement of cages within a site had an influence on survival. Egg production and vitellogenin concentrations $(n=18$ in-situ breeding chamber pseudoreplicates per site) between locations (upstream versus downstream) were compared using standard t-tests. Egg production was calculated as the average number of eggs laid per female per day. A p-value less than 0.05 was considered significant in all statistical analyses conducted.

Acute WET test survival data were analyzed using a trimmed Spearman-Karber method (USEPA, 2002a). This is a non-parametric method of calculating a point estimate that can be useful in comparisons of toxicity among chemicals for a given species, or of toxicity among species for a given chemical. Chronic WET test survival data were analyzed using a one-way analysis of variance (ANOVA) to determine if there was a significant difference among treatments, followed by Tukey's multiple comparison test to determine which treatments were significantly different from each other (if the ANOVA was significant). Chronic WET test growth data were not statistically analyzed because we mistakenly pooled fish from all replicates for each treatment.

Laboratory reproduction assay survival data were compared using contingency table analysis to determine if effluent had an influence on survival. Egg production was compared between treatments using a t-test. Vitellogenin concentrations were not statistically analyzed because some diluted sample concentrations were greater than the highest standard in the test kit.

\section{Results}

\section{Field Reproduction Assay}

Survival of fathead minnows was not significantly different between upstream and downstream sites $(p=0.315)$. Only one fish died during the course of the study, a female in one of the upstream cages. Egg production was not significantly different between upstream and downstream sites $(p=0.488)$. A total of 15,631 eggs were produced upstream, and 15,726 downstream over the course of the 24-d experiment. Mean egg production per female per day ranged from 0 to 54.34 at the upstream site, and from 0 to 59.71 at the downstream site. Egg production was tied to water temperature. Egg production decreased at both sites when water temperature dropped below $19^{\circ} \mathrm{C}$ (Figure 1). The average water temperature was $21.91^{\circ} \mathrm{C}$ at the upstream site and $21.96{ }^{\circ} \mathrm{C}$ at the downstream site. There was no significant 
difference in temperature between sites $(p=0.470)$. Vitellogenin was detected in male fish, but at both the upstream and downstream sites (Table 1). There was no significant difference in vitellogenin concentrations between sites if all males (producers and non-producers) are included in the analysis $(p=0.124)$. However, if only vitellogenin producers are included in the analysis, vitellogenin concentrations were higher in fish caged downstream of the WWTP effluent pipe $(p=0.039)$.

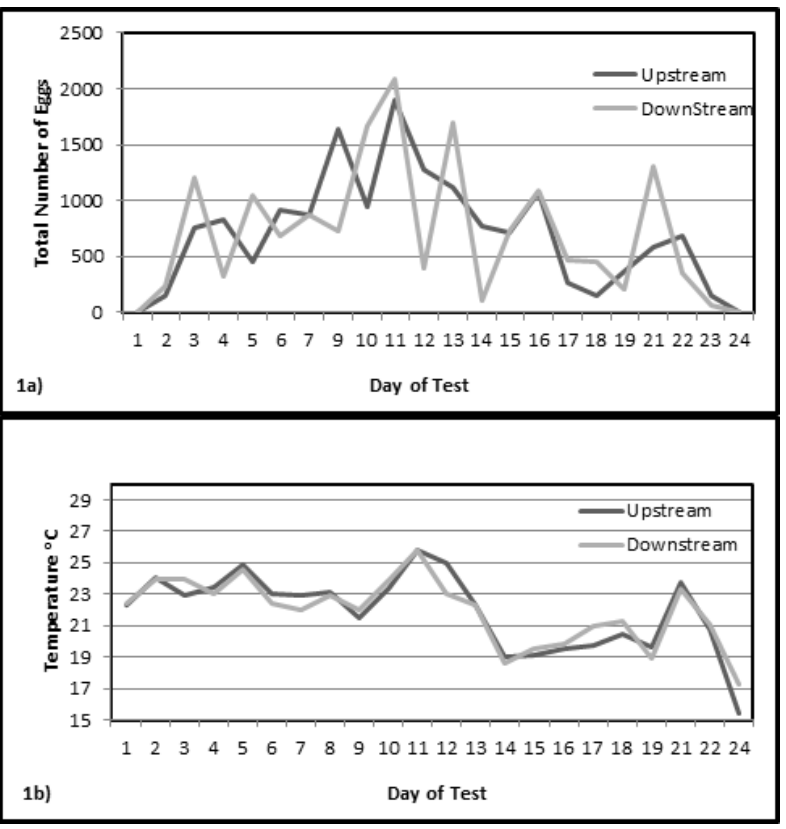

Figure 1: a) Total egg production, and b) water temperature at sites located upstream and downstream of the WWTP during the 24-d field reproduction assay conducted with fathead minnows. Egg production was not measured on day 8 because of high water. Temperature was not measured on days 20 or 23 .

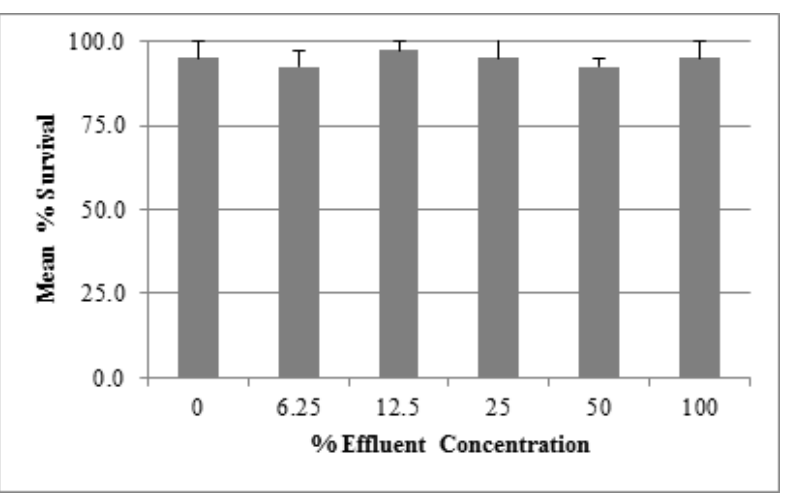

Figure 2: Mean percent survival of fathead minnows $(n=4)$ exposed to different concentrations of effluent for four days in the acute WET test. Error bars equal +1 standard error.
Acute and Chronic WET Tests

In the acute WET test, there was no significant difference in survival among treatments $(p=0.312$; Figure 2). Given the high survival, we were not able to calculate an LC50 value.

In the chronic WET test there was no significant difference in survival among treatments $(p=0.302$; Figure 3$)$. Total dry weight was determined for each treatment (Figure 4), but not statistically compared because fish in all four replicate tanks were combined for each treatment.

Table 1: Vitellogenin concentrations in male fathead minnows $(n=18)$ caged upstream and downstream of the Whitewater WWTP during the 24-d caged reproduction assay. LP indicates lower than necessary $(10 \mu \mathrm{L})$ blood plasma was collected.

\begin{tabular}{cc}
\hline Upstream Males & Downstream Males \\
Vitellogenin $(\mathrm{ng} / \mathrm{mL})$ & Vitellogenin $(\mathrm{ng} / \mathrm{mL})$ \\
\hline $\mathbf{0}$ & 0 \\
$\mathbf{0}$ & 0 \\
$\mathbf{0}$ & 1,044 \\
$\mathbf{L P}$ & 0 \\
$\mathbf{0}$ & 783 \\
$\mathbf{0}$ & $\mathrm{LP}$ \\
$\mathbf{1 , 6 2 5}$ & 2,402 \\
$\mathbf{1 3 3}$ & 0 \\
$\mathbf{5 2 2}$ & 2,993 \\
$\mathbf{0}$ & 0 \\
$\mathbf{0}$ & 0 \\
$\mathbf{2 3 7}$ & 0 \\
$\mathbf{0}$ & 0 \\
$\mathbf{0}$ & 0 \\
$\mathbf{2 1 3}$ & 0 \\
$\mathbf{0}$ & 825 \\
$\mathbf{4 7 0}$ & 0 \\
$\mathbf{0}$ & 0 \\
\hline
\end{tabular}

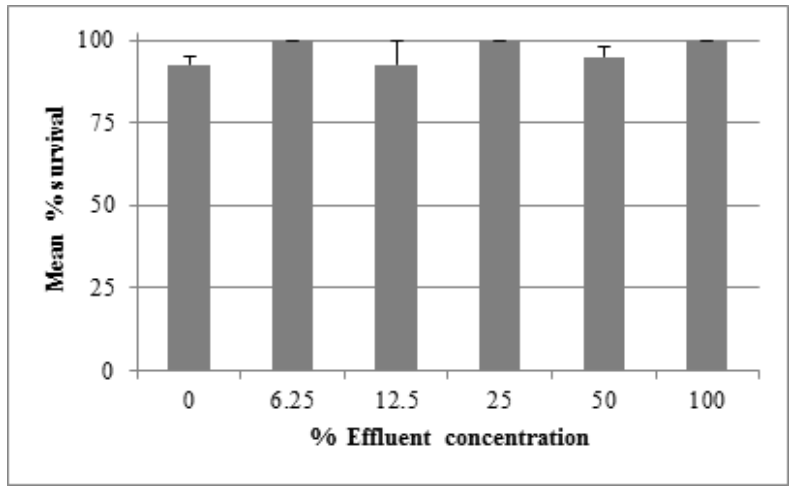

Figure 3: Mean percent survival of fathead minnows $(n=4)$ exposed to different concentrations of effluent for seven days in the chronic WET test. Error bars equal +1 standard error. 


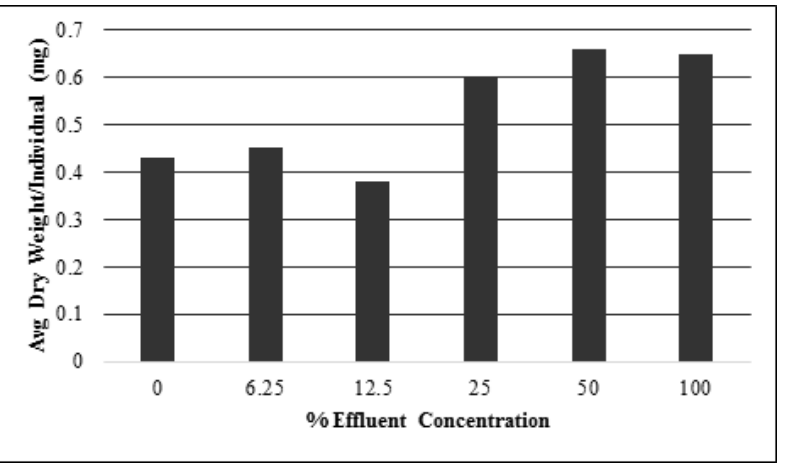

Figure 4: Average dry weight per individual larval fathead minnow exposed to different concentrations of effluent for seven days in the chronic WET test.

\section{Laboratory Reproduction Assay}

Survival of fathead minnows was not significantly different between control and effluent treatments $(p=0.316)$. Only one fish died during the course of the study, a female in one of the control aquaria. Egg production was not significantly different between treatments $(p=0.262)$, but was much lower in this laboratory reproduction assay than in the field reproduction assay. A total of only 1,075 and 525 eggs were produced in the control and effluent treatments, respectively. Mean egg production per female per day ranged from 0 to 21.25 in the control and from 0 to 17.85 in the effluent treatment. Vitellogenin was detected in all male fish in both treatments (Table 2). Some diluted samples exceeded the highest standard of $50 \mathrm{ng} / \mathrm{mL}$ and a precise concentration of vitellogenin within those samples could not be calculated. Because of this, it was not possible to determine if there was a significant difference in vitellogenin concentrations between treatments.

Table 2: Vitellogenin concentrations in male fathead minnows $(n=8)$ exposed to control or $100 \%$ effluent treatments in a 21-day laboratory reproduction assay.

\begin{tabular}{cc}
\hline $\begin{array}{c}\text { Control Males } \\
\text { Vitellogenin }(\mathrm{ng} / \mathrm{mL})\end{array}$ & $\begin{array}{c}\text { Effluent Males } \\
\text { Vitellogenin }(\mathrm{ng} / \mathrm{mL})\end{array}$ \\
\hline $\mathbf{1 4 5 0}$ & $>1950$ \\
$\mathbf{1 0 7 0}$ & $>1950$ \\
$>\mathbf{1 9 5 0}$ & $>1950$ \\
$\mathbf{6 3 0}$ & $>1950$ \\
$\mathbf{1 8 6}$ & $>1950$ \\
$>\mathbf{1 9 5 0}$ & 1904 \\
$>\mathbf{1 9 5 0}$ & $>1950$ \\
$>\mathbf{1 9 5 0}$ & 1945 \\
\hline
\end{tabular}

\section{Discussion}

Survival of fathead minnows was not impacted by effluent Effluent discharged from the Whitewater WWTP to Whitewater Creek had no significant impact on survival of fathead minnows. Fathead minnows are widely used as a model organism in toxicity tests, and results of studies conducted with fathead minnows are often used as an indication of the likelihood of effects on other aquatic organisms. However, fathead minnows can be more tolerant to some types of contaminants than many other aquatic organisms (Dwyer et al., 2005), and thus may not always be the best indicator species. In addition, fathead minnows are reared in the laboratory for use in toxicity tests, and after so many generations, may have decreased genetic diversity and genotypes that are more or less susceptible to contaminants (Chapman, 2000). Sublethal endpoints may be a better indicator of effects than survival alone. Other researchers have shown effluent may affect sperm motility (Schoenfuss, Levitt, Rai, Julius \& Martinovic, 2010), gonadosomatic index and secondary sexual characteristics (Barber, Lee, Schwackhamer \& Schoenfuss, 2007), and result in genotoxic and immunotoxic effects (Liney et al., 2006).

\section{Growth of fathead minnows was not impacted by effluent}

Because fish from different replicates were combined for each treatment, it was not possible to statistically compare final dry weight of fish among effluent treatments. Fish did appear to weigh more in the higher effluent treatments, and it is possible that organic matter in the effluent acted as a food source for the fish. However, differences may not have been significant. Liney et al. (2006) found no significant difference in growth of fish among effluent concentrations. Siwik, VanMeer, MacKinnon and Paszkowski (2000) found no significant difference in dry weight of larval fish exposed to effluent in laboratory studies, but did find a significant difference in dry weight of larval fish exposed to effluent in outdoor mesocosm studies. A review of commonly measured endpoints used in 173 toxicity studies showed growth as the least significant endpoint measured, with only $14 \%$ of tests showing any significant difference, which raises the question as to whether growth is always a useful endpoint (Woltering, 1984).

Egg production by fathead minnows was not impacted by effluent

There was no significant difference in egg production between fathead minnows exposed to effluent and those not exposed to effluent in both the field and the laboratory, although we observed greater egg production in the field reproduction assay. This could be due to abiotic (e.g., variation in temperature and water flow) and/or biotic (e.g., increased food availability) factors found in the field (Chapman, 2000). The decrease in egg production observed at the downstream site when water temperature dropped below $19^{\circ} \mathrm{C}$ was similar to that observed in another caged fathead minnow study conducted by Corsi et al.(2011).

\section{Vitellogenin was detected in male fathead minnows}

Vitellogenin was detected in male fathead minnows in both the field and laboratory reproductive assays, indicating exposure to estrogens or estrogen mimics. In the field study, five of the 18 male fish caged downstream produced vitellogenin. However, six of the 18 male fish caged upstream of the Whitewater WWTP also produced vitellogenin. We did not expect to find vitellogenin in upstream fish. Concentrations of vitellogenin were generally 
higher in fish located downstream of the Whitewater WWTP, so it is possible that estrogens or estrogen mimics in the effluent are inducing vitellogenin synthesis in male fish. Vajda et al. (2008) found vitellogenin in native white suckers collected both upstream and downstream of a WWTP at sites divided by a dam in Colorado, with higher concentrations downstream. In a laboratory study, Barber et al. (2007) found increased vitellogenin concentrations in fathead minnows exposed to WWTP effluent compared to those exposed to a groundwater control.

There are likely other sources of estrogens and/or estrogen mimics to Whitewater Creek. These may include leaking septic tanks from homes located around Whitewater Lake, which flows into Whitewater Creek. Because Whitewater Creek is a fourth order stream in the area where the study was conducted, tributaries may also contribute these chemicals. Land surrounding Whitewater Creek and its tributaries include both urban and agricultural uses. There are also several culverts that discharge runoff to Whitewater Creek.

It is likely there are additional sources of estrogens and/or estrogen mimics in the laboratory as well. All male fish used in the laboratory reproductive assay (both control and effluent-treated fish) contained vitellogenin, and concentrations of vitellogenin were higher in male fish used in the laboratory study than in the field study. In fact, we were unable to precisely quantify vitellogenin concentrations for most of the male fathead minnows in the laboratory 21day reproduction assay because concentrations of diluted samples were higher than our highest standard. The ELISA test kit recommends making three different dilutions, 1:50, 1:5,000, and 1:500,000. However, because funding for ELISA kits was limited, a single dilution of 1:50 was used to allow for duplication of each sample. Estrogens and their mimics have been found in commercial food sources such as pelleted trout chow (Ishibashi et al., 2002). Air tubing may contain phthalates, which have been shown to be estrogenic (Soto et al., 1995). In addition, the filters were held in polycarbonate plastic chambers, and polycarbonate plastic may contain bisphenol-A (BPA), which has also been shown to be estrogenic (Lindholst, Pedersen \& Pedersen 2000). Thus, while vitellogenin may be a sensitive biomarker that indicates exposure to estrogenic chemicals, it may not be as specific as some other biomarkers (e.g., aminolevulinic acid dehydratase, which is inhibited only by lead; Wigfield, Wright, Chakrabarti, and Karwowska, 1986), simply because there are so many chemicals that may act as estrogen mimics.

As with all biomarkers, it is important to know whether production of vitellogenin merely indicates exposure or whether it indicates adverse effect. Crago, Corsi, Weber, Bannerman and Klaper (2011) suggest vitellogenin be utilized in tandem with other biomarkers such as glutathione Stransferase (GST). GST can be used as a biomarker of stress for a variety of contaminants or mixtures of contaminants. It may be helpful to look for additional evidence of endocrine disruption at the tissue-level. For example, gonads can be excised, weighed and used to calculate a gonadal somatic index (Barber et al., 2007), and testes can be examined for the presence of oocytes. Future studies should include the use of a variety of biomarkers and indices to allow a more complete analysis of sublethal adverse effects.
Future studies that focus on effects of WWTP effluents should also consider timing. The field reproduction study was conducted from late August to early September, and the laboratory reproduction assay was conducted in March. The city of Whitewater increases in population from September to May with college students. This increases the volume of raw influent at the WWTP and also the volume and possibly concentrations of PPCPs. The majority of our field reproduction study was conducted in summer, before most of the college students were on campus. Our laboratory reproduction study was conducted at a time when the student population was high for the duration of the test. Had we conducted the field reproduction study during the semester, we may have observed different results. However, since egg production is dependent on water temperature, a later (fall) or earlier (spring) test start date could have impacted egg production.

Results of our study may differ from similar studies conducted at other WWTPs in the future, depending on the type of WWTP processes employed. Some treatment processes can remove more PPCPs than others (Servos et al., 2005; Yang, Flowers, Weinberg \& Singer 2011). In addition, the chemical makeup of the influent and the efficiency of treatment processes can vary over time.

In conclusion, both field and laboratory studies indicate effluent from the Whitewater WWTP is unlikely to cause adverse effects on survival of, or egg production by the fathead minnow, an important forage fish species. Most of the male fish caged upstream and downstream of the WWTP did not produce vitellogenin. However, if we look at only those male fish that did produce vitellogenin in the field study, higher concentrations were detected in males housed downstream of the Whitewater WWTP discharge pipe. Future studies should consider other sublethal endpoints such as gonadal somatic index and presence of ovotestes. If production of vitellogenin in male fathead minnows ultimately leads to decreased reproduction and changes in population size, there could be cascading effects on other members of the aquatic community.

\section{Acknowledgments}

Funding was provided by grants from the Merck/AAAS Summer Undergraduate Research Program, University of Wisconsin-Whitewater (UWW) Summer Undergraduate Research Fellowship Program, and the UWW Undergraduate Research Program. Special thanks to Dean Mary Pinkerton, Dr. Bruce Eshelman, Dr. Paul House, Dr. Catherine Chan, Steve Corsi, Dr. Jocelyn Hemming, Dawn Perkins, Lindsey Schulte, Joe Vance and Tim Reel.

\section{References}

Ankley, G. T., Jensen, K. J, Kahl, M. D., Korte, J. J., \& Makynen, E. A. (2001). Description and evaluation of a short-term reproduction test with the fathead minnow (Pimephales promelas). Environmental Toxicology and Chemistry, 20, 1276-1290.

Barber, L. B., Lee, K. E., Schwackhamer, D. L., \& Schoenfuss, H. L. (2007). Reproductive responses of male fathead minnows exposed to wastewater treatment plant 
effluent, effluent treated with XAD* resin, and an environmentally relevant mixture of alkylphenol compounds. Aquatic Toxicology, 82, 36-46.

Chapman, P. M. (2000). Whole effluent toxicity testingUsefullness, level of protection, and risk assessment. Environmental Toxicology and Chemistry, 19, 3-13.

Corsi, S. R., Klaper, R. D., Weber, D. N., \& Bannerman, R. T. (2011). Water-and-sediment-quality effects on Pimephales promelas spawning vary along agricultural-tourban land-use gradient. Science of the Total Environment, 409, 4847-4857.

Crago, J., Corsi, S. R., Weber, D., Bannerman, R., \& Klaper, R. (2011). Linking biomarkers to reproductive success of caged fathead minnows in streams with increasing urbanization. Chemopshere, 82, 1669-1674.

Dwyer, F. J., Meyer, F. L., Sappington, L. C., Buckler, D. R., Bridges, C. M., Greer, I. E., Hardesty, D. K., et al. (2005). Assessing contaminant sensitivity of endangered and threatened aquatic species: Part 1. Acute toxicity of five chemicals. Archives of Environmental Contamination and Toxicology, 48, 143-154.

Ishibashi, H., Koshiishi, T., Moriwaki, T., Tachibana, K., Tsuchimoto, M., Soyano, K., et al. (2002). Induction of plasma vitellogenin synthesis by the commercial fish diets in male goldfish (Carassius auratus) and dietary phytoestrogens. Journal of Health Sciences, 48, 427-434.

Ishibashi, H., Tachibana, K., Tsuchimoto, M., Soyano, K., Ishibashi, Y., Nagae, M., et al. (2001). In vivo testing system for determining the estrogenic activity of endocrine disrupting chemicals (EGCs) in goldfish (Carassius auratus). Journal of Health Science, 47, 213-218.

Kolpin, D. W., Furlong, E. T., Meyer, M. T., Thurman, E. M., Zaugg, S. D., Barber, L. B., \& Buxton, H. T. (2002). Pharmaceuticals hormones and other organic wastewater contaminants in U.S. streams, 1999-2000: A national reconnaissance. Environmental Science and Technology, 40, 1202-1211.

Körner, W., Bolz, U., Sussmuth, W., Hiller, G., Schuller, W., Hanf, V., \& Hagenmaier, H. (2000). Input/output balance of estrogenic active compounds in a major municipal sewage plant. Chemosphere, 40, 1131-1142.

Lindholst, C., Pedersen, K. L., Pedersen, S. N. (2000). Estrogenic response of bisphenol-A in rainbow trout (Oncorhynchus mykiss). Aquatic Toxicology, 48, 87-94.

Liney, K. E., Hagger, J. A., Tyler, C. R., Depledge, M. H., Galloway, T. S., \& Jobling, S. (2006). Health effects in fish and long term exposure to effluents from wastewater treatment works. Environmental Health Perspectives, 114, 81-89.

Löffler, D., Römbke, J., Meller, M., \& Ternes, T. (2005). Environmental fate of pharmaceuticals in water/sediment systems. Environmental Science and Technology, 39, 52095218.

Munderlin, M. (2013). Whitewater Wastewater Treatment Plant. Retrieved January 24, 2013, from http://www.whitewaterwi.gov/images/stories/public_works/wastewater/WWTP_T our.pdf

Schoenfuss, H. L., Levitt, J. T., Rai, R., Julius, M. L., \& Martinovic, D. (2010). Treated wastewater effluent reduces sperm motility along an osmolality gradient. Archives of
Environmental Contamination and Toxicology, 56, 397 407.

Servos, M. R., Bennie, D. T., Burnison, B. K., Jurkovic, A., McInnis, R., Neheli, T., et al. (2005). Distribution of estrogens, 17B-estradiol and estrone, in Canadian municipal wastewater treatment plants. Science of the Total Environment, 336, 155-170.

Siwik, P. L., Van Meer, T., MacKinnon, M. D., \& Paszkowski, C. A. (2000). Growth of fathead minnows in oils and-processed wastewater in laboratory and field. Environmental Toxicology and Chemistry, 19, 1837-1845.

Soto, A., Sonnenschein, C., Chung, K. L., Fernandez, M. F., Olea, N., \& Serrano, F. O. (1995).

The E-SCREEN assay as a tool to identify estrogens: An update on estrogenic environmental pollutants. Environmental Health Perspectives, 103(Suppl 7), 113122.

USEPA. (2002a). Methods for measuring the acute toxicity of effluents and receiving waters to

freshwater and marine organisms. Fifth edition. (USEPA Publication No. EPA-821-R-02-012). Washington, DC.

USEPA. (2002b). Short-term methods for estimating the chronic toxicity of effluents and

receiving waters to freshwater organisms. Fourth edition. (USEPA Publication No. EPA-821-R-02-013). Washington, DC.

USEPA. (2007). Method 1694: Pharmaceuticals and personal care products in water, soil,

sediment, and biosolids by HPLC/MS/MS. (USEPA Publication No. EPA-821-R-08-002). Washington, DC.

Vajda, A. M., Barber, L. B., Gray, J. L., Lopez, E. M., Woodling, J. D., \& Norris, D. O. (2008). Reproductive disruption in fish downstream from an estrogenic wastewater effluent. Environmental Science and Technology, 42, 3407-3414.

Wigfield, D. C., Wright, S. C., Chakrabarti, C. L., \& Karwowska, R. (1986). Evaluation of the relationship between chemical and biological monitoring of low level lead poisoning. Journal of Applied Toxicology 6, 231-235.

Woltering, D. M. (1984). The growth response in fish chronic and early life stage toxicity tests: a critical review. Aquatic Toxicology, 5, 1-21.

Yang, X., Flowers, R. C., Weinberg, H. S., \& Singer, P. C. (2011). Occurrence and removal of pharmaceuticals and personal care products (PPCPs) in an advanced wastewater reclamation plant. Water Research, 45, 5218-5228.

Zorita, A., Martensson, L., \& Mathiasson, L. (2009). Occurrence and removal of pharmaceuticals in a municipal sewage treatment system in the south of Sweden. Science of the Total Environment, 407, 2760-2770. 